\title{
ALICE YURA, TRANSFORMA: GÊNERO, ABJEÇÃO, PERFORMATIVIDADE E PERFORMANCE
}

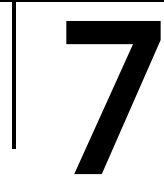

\section{ALICE YURA, TRANSFORM: GENDER, ABJECTION, PERFORMATIVITY AND \\ PERFORMANCE}

\author{
BIZIAK, Jacob dos Santos \\ Doutor em Estudos Literários pela Universidade Estadual Júlio de Mesquita Filho, campus de \\ Araraquara \\ Docente do Instituto Federal de São Paulo e da Universidade Estadual Júlio de Mesquita Filho, \\ campus de Araraquara \\ E-mail: jacob.biziak@ifpr.edu.br \\ ORCID ID: https://orcid.org/0000-0001-9495-5171
}

\section{ZOPPI FONTANA, Mónica Graciela}

Livre Docente em Linguística pela Universidade Estadual de Campinas

Docente da Universidade Estadual de Campinas

E-mail: monzoppi@unicamp.br

ORCID ID: https://orcid.org/0000-0001-9823-0696

\section{RESUMO}

Este artigo, a partir de um entremeio entre obras de Michel Pêcheux, Judith Butler e da artista plástica Alice Yura, busca reconsiderar a abjeção enquanto marca de alguns corpos, gêneros e vidas. Diferentemente, sustentamos que não há corpo que não porte abjeção (da ordem do real) e precariedade (da ordem do simbólico e do imaginário). Propomos, então, a abjeção como trabalho de não acabar das corporeidades que não cansa de não se inscrever nos movimentos da história, na materialidade da ideologia e da linguagem.

Palavras-chave: gênero; abjeção; performatividade; performance.

\section{ABSTRACT}

This article, based on an interweaving of works by Michel Pêcheux, Judith Butler and artist Alice Yura, seeks to reconsider abjection as a mark of some bodies, genres and lives. In contrast, we maintain that there is no body that does not carry abjection (of the real order) and precariousness (of the symbolic and imaginary order). We propose, then, abjection as a 
work of not ending corporeality that never tires of not being inscribed in the movements of history, in the materiality of ideology and language.

Keywords: gender; abjection; performativity; performance.

\section{EFEITOS DE INTRODUÇÃO}

Eu determino que termine aqui e agora

Eu determino que termine em mim, mas não acabe comigo Determino que termine em nós e desate

E que amanhã, que amanhã possa ser diferente pra elas

Que tenham outros problemas e encontrem novas soluções E que eu possa viver nelas, através delas e em suas memórias (DA QUEBRADA, Linn, 2020)

Este artigo inicia-se com uma pergunta e, provavelmente, terminará com diversas outras. Isso, talvez, por conta da plasticidade do corpus de análise, mas, também, pela perspectiva que recusa a ideia de "representação" enquanto relação de referência entre "as palavras e as coisas", como se entre elas houvesse um caminho reto, direto e transparente. Assim, pensamos em certo diálogo com o que Vladimir Safatle, outrora, argumentou: "Identidades sexuais não deveriam ser pensadas como representações suportadas pela estrutura binária de sexos. Tratava-se, ao contrário, de tentar escapar da própria noção de representação através de uma teoria performativa do sexual" (SAFATLE, 2015, p. 186, grifo do autor).

Dessa forma, nossa posição teórica e política para construção deste gesto de leitura começou a ser elaborada por meio de um contato que foi sendo construído com as obras de Judith Butler (1998, 2002, 2003, $2014,2015 a, 2015 b, 2017)$ a respeito de gêneros, corpos e precarização da vida. Carla Rodrigues (2017) bem nos lembra a respeito da recepção dos textos da filósofa estadunidense no Brasil: durante anos, extrema e praticamente só marcada por "questões de gênero". Somente a partir de 2014, com a tradução de outros livros, para além de Problemas de gênero (1998), Butler começou a ser conhecida, em nosso país, também na discussão de outras temáticas, tidas, na academia, como mais "universais" na filosofia, como a ética e a política. Talvez, um fio condutor entre seus escritos seja a postura de questionamento e problematização de uma visada sobre a relação entre sujeitos, linguagem e realidades que não seja performativa. Em outros termos, tal relação não pode ser tomada como cópia passiva de modelos pré-fabricados de realidade, 
mas como como repetição, pela enunciação de sujeitos, de enunciados que circulam socialmente produzindo valores, sentidos.

Para este trabalho, buscamos pensar o conceito de abjeto/abjeção - conforme Butler o apresenta (2002) - a partir da relação com a performatividade e a performance. Nossa proposta de trabalho consiste em estabelecer um diálogo entre Judith Butler e Michel Pêcheux, buscando redefinir a noção de abjeção proposta por Butler. Fazemos isso afetados por uma posição de leitura em relação a três obras da artista Alice Yura ${ }^{1}$. Tendo em vista proposições de Judith Butler (sobre performatividade, gênero e corpo) e de Michel Pêcheux (sobre, principalmente, a relação entre intradiscurso e interdiscurso), interrogamos sobre como o abjeto/a abjeção pode funcionar, tendo em vista uma perspectiva discursiva. Seria possível o abjeto/a abjeção ser parafraseado como aquilo que na ordem do(s) corpo(s) é marginalizado, excluído, das posições-sujeito hegemônicas? Mais, ainda: seria a abjeção algo da ordem do que pode ser excluído, expulso? Nossa ideia, então, é pensar isso a partir de um trabalho de compreensão do funcionamento da linguagem, do corpo e dos sentidos em três obras performáticas de Alice Yura. O recorte e a escolha baseiam-se, inicialmente, na forma mais explícita de como a corporeidade é posta ao olhar do leitor nas imagens construídas pela artista. Além disso, como veremos, trata-se de obras nas quais o leitor é capturado e posto em deriva, também, pela via do olhar: seja pelo possível estranhamento do que ele vê; seja por ser interpelado pela construção dos corpos das/nas imagens, que lançam miragens direcionadas ao suposto leitor/expectador.

\section{JUDITH BUTLER E MICHEL PÊCHEUX: SUJEITO E ESTADO}

Em Problemas de gênero (2003), Butler empreende um trabalho de releitura do conceito de performativo (retirado de Austin) para pensar as identificações de gênero. Isso é feito a partir de uma recepção da

\footnotetext{
1. Segundo o site Pivô: "1990, vive e trabalha em Aparecida do Taboado e Campo Grande. Sua formação acadêmica e principais exposições e mostras foram em Campo Grande. Graduada em 2011 em artes visuais pela UFMS e 2013 finalizou uma pós pelo Senac em produção em artes visuais e cultura. Seus trabalhos possuem uma forte ligação biográfica ligadas às questões de afeto e intimidade, do corpo, identidade e alteridade, biologia, política e sociedade. A performance tem destaque em sua produção, no entanto, a artista também realiza trabalhos em outras linguagens. Foi uma das idealizadoras e curadoras do Festival IPêrformático (primeiro festival de Campo Grande - MS) que neste ano (2019) teve sua segunda edição. Participa do circuito interno do Mato Grosso do Sul de arte nas principais instituições de arte e cultura do estado: Museu de Arte Contemporânea (MARCO), Centro Cultural José Octávio Guizzo, Teatro Glauce Rocha, MIS, Armazém Cultural entre outras. Sua foto-instalação Com e Sem? pertence ao acervo do MARCO desde 2014. E, com isso e com toda sua produção foi a primeira mulher transexual a expor nas principais instituições artísticas e culturais do seu estado e integrar ao acervo cultural do Mato Grosso do Sul" (Alice Yura. Pivô, 2020. Disponível em: https://www.pivo.org.br/artistas/alice-yura/. Acesso em: 11 de maio de 2020).
} 
filósofa tendo em vista alguns pilares, como Derrida, Lacan e Foucault. Logo, não se trata de uma "simples" retomada do conceito, mas de o reinscrever a partir do problema de se tomar os gêneros como "naturais", "destinos definidos". O performativo é reelaborado para se pensar em quais condições são possíveis sujeitos generificados. Este conceito vai sendo retomado ao longo de todas as publicações de Butler que, com o passar do tempo, expande, também, seus espectros de reflexão: a materialidade dos corpos; as guerras contemporâneas; as democracias; o neoliberalismo; o sionismo etc.

Há um momento - especialmente em Relatar a si mesmo (2015a) em que a filósofa tenta relacionar tal condição provisória (logo, elemento de precariedade das vidas) dos sujeitos com os escritos de Louis Althusser, especialmente com o conceito de interpelação. No entanto, nesta obra, Butler acaba não mencionando - e, portanto, ignorando - a base epistemológica de tal conceito na obra de Althusser (2008). O filósofo francês propõe a interpelação a partir de um forte fundamento em que pensa a estrutura do Estado não a partir somente e/ou diretamente da questão do poder (como se dá em Foucault, ao qual Butler recorre para pensar Estado e discurso), mas da relativa independência do econômico em relação ao político, no qual o aparelho jurídico funciona de forma paradoxal, e a forma-sujeito de direitos comparece como livre, produzindo efeitos de unidade na dispersão de posições. Essa leitura sintomal empreendida por Althusser (1979) em Marx, retoma e desloca termos como ideologia, levando em conta a proposta do pensador alemão sobre história e formações sociais. A partir desse deslocamento, é realizada uma proposta de leitura da ideologia em relação ao inconsciente lacaniano, não como se fossem correspondentes, mas como relação de analogia.

A pontuação anterior é importante não com a finalidade de apontar "defeitos" na leitura de Judith Butler, mas para analisarmos a questão epistemológica que envolve cada autor que vai sendo retomado e deslocado nas proposições da filósofa. Além disso, tais considerações ajudam a fortalecer a nossa proposta de ponte teórica entre Butler e Pêcheux: ela se dá via Althusser, desde que consideradas as condições de produção da obra deste. Assim, colocar Butler e Pêcheux em entremeio significa considerar e rever a entrada da pensadora estadunidense na obra de Althusser, na maneira como isso é textualizado em suas reflexões. Em outras palavras, dialogamos com Butler, mas considerando a materialidade da língua e da ideologia. 
Tal consideração epistemológica impacta à medida em que, neste nosso trabalho, vamos reinscrevendo algumas considerações feitas por Butler. Em Quem canta o Estado-nação? (2018), a filósofa coloca sua preocupação em pensar o "estado" dos sujeitos sem "Estado" (este jogo entre significantes ocorre na obra, inclusive). Nesse sentido, em mais de um momento, argumenta-se a respeito do "pertencimento" a um Estadonação, e da condição precária de se estar "fora" deste. No entanto, para a análise de discurso de Pêcheux, não há um sujeito fora da ideologia, a não ser em uma dimensão imaginária. Isso quer dizer que a abjeção, em suas diversas manifestações (gêneros, sexualidades, imigrantes etc.), não implica estar "fora" da ideologia e das formas de interpelação e individuação instituídas pelo Estado em determinadas condições de produção. Trata-se de algo não possível, tendo em vista que esse sujeito, aparentemente "fora" do Estado, compõe também o Estado à medida em que dá visibilidade à falta que o constitui (ORLANDI, 2013) e estabelece relações de diferença que permitem a legibilidade de outras formas de "(não)ser sujeito (de direito)"; embora sempre-já sujeitos ideológicos. Logo, algumas formulações de Butler podem ser deslocadas em aspectos que, em relação à análise de discurso, soam nebulosas.

A tradução proposta por Guacira Lopes Louro (2007) sobre o prefácio de Cuerpos que importan (2002), durante muitos anos ${ }^{2}$ ajudou a construir a recepção no Brasil da obra de Judith Butler, especialmente no que esta propõe sobre a performatividade de gêneros e corpos. Já neste momento, demarca-se a tentativa de a filósofa responder ao que teria sido uma "falta" de Problemas de gênero (1998): qual a relação entre materialidade e performatividade de gênero? Teria a sua reflexão excluído a materialidade?

Vale a pena retomar parte da argumentação produzida:

Mas como, então, a noção de performatividade de gênero se relaciona com essa concepção de materialização? No primeiro caso, a performatividade deve ser compreendida não como um "ato" singular ou deliberado, mas, ao invés disso, como a prática reiterativa e citacional pela qual o discurso produz os efeitos que ele nomeia. O que, eu espero, se tornará claro no que vem a seguir é que as normas regulatórias do "sexo" trabalham de uma forma performativa para constituir a materialidade dos corpos

2. Somente em 2019, publicou-se a tradução integral do livro de Butler (BUTLER, Judith. Corpos que importam: os limites discursivos do "sexo". São Paulo: N4 Edições, 2019). 
e, mais especificamente, para materializar o sexo do corpo, para materializar a diferença sexual a serviço da consolidação do imperativo heterossexual.

Nesse sentido, o que constitui a fixidez do corpo, seus contornos, seus movimentos, será plenamente material, mas a materialidade será repensada como o efeito do poder, como o efeito mais produtivo do poder. Não se pode, de forma alguma, conceber o gênero como um constructo cultural que é simplesmente imposto sobre a superfície da matéria - quer se entenda essa como o "corpo", quer como um suposto sexo. Ao invés disso, uma vez que o próprio "sexo" seja compreendido em sua normatividade, a materialidade do corpo não pode ser pensada separadamente da materialização daquela norma regulatória. O "sexo" é, pois, não simplesmente aquilo que alguém tem ou uma descrição estática daquilo que alguém é: ele é uma das normas pelas quais o "alguém" simplesmente se torna viável, é aquilo que qualifica um corpo para a vida no interior do domínio da inteligibilidade cultural. (BUTLER, 2007, p. 154)

A argumentação, neste trecho, atua de maneira a situar materialidade em uma outra possiblidade de leitura: não como a forma "desde sempre" possível e óbvia e nem só como uma "construção" que não é volitiva nem intencional, mas, principalmente, como efeitos ${ }^{3}$ instáveis de uma norma. A partir de uma articulação com propostas teóricas de Michel Pêcheux, entendemos que esses efeitos são produzidos pela repetição histórica - ou seja, repetição com interpretação (ORLANDI, 1996) - a partir da inscrição em posições-sujeito. A sua situação é ignorada pelos sujeitos mesmos, cuja origem não pode ser recuperada (BUTLER, 2015a); Butler considera o assujeitamento e o caráter produtivo do poder (BUTLER, 2017), cujo funcionamento é, para a autora, paradoxal, dando margem à manutenção de hierarquias e à possibilidade de resistências.

3. Portanto, pela nossa proposta, pensando Butler com Pêcheux, a materialidade não se refere diretamente à construção de alguma sequência inteligível. Sendo ela somente compreensível pelos efeitos que produz na equivocididade da/na história, é importante não tornar "materialidade" sinônimo de "construção" ou de "algo concreto". Digo isso porque, inclusive, o real existe, e isso diz respeito às condições materiais concretas de existência dos sujeitos, da linguagem e dos processos discursivos. Portanto, concordamos com Pêcheux, quando ele conceitua materialidade discursiva como: "nível de existência sócio-histórica, que não é nem a língua, nem a literatura, nem mesmo as 'mentalidades' de uma época, mas [...] as condições verbais de existência de um objeto (científicos, estéticos, ideológicos...) em uma conjuntura histórica dada" (2015, p. 151-152, grifos nossos). Inclusive, não se deve olvidar de que os dispositivos teóricos de acesso a tal materialidade são, também, materialmente produzidos. 
Mais uma vez, não podemos nos esquecer de que Butler argumenta filiada a proposições de Michel Foucault. Logo, a partir da articulação que, neste trabalho, propomos entre a filósofa e Pêcheux, a questão do assujeitamento é pensada a partir do funcionamento da Ideologia na sua relação com os Aparelhos Ideológicos do Estado, tal como apontado por Althusser (2008) e retomado por Pêcheux (1998). Ou seja, a relação imaginária com a forma-sujeito de direito capitalista enquanto possível pelo equívoco na história e pela falha no simbólico.

Entendemos, então, que Butler, no citado texto, argumenta e propõe que não deixou de abordar a materialidade dos corpos e dos gêneros, mas que, talvez, não tenha frisado como ela deve ser tomada, ainda mais sendo um termo cuja memória favorece deslocamentos diversos, inclusive os não previstos pela enunciação de Cuerpos que importan (2002). Há materialidade histórica, e não simples "matéria concreta estável", o que contribuiria para resgatar o imaginário do corpo-origem, o que pode e deve ser copiado como norma, como marca da vida vivível (BUTLER, 2015b). Além disso, ao nosso ver, tal imaginário não pode ser compreendido a partir de uma compreensão de assujeitamento como subordinação a/por relações estratégicas de poder (o que remete à vinculação foucaultiana de Butler). Diferentemente, tal imaginário inscreve-se a partir de relações contraditórias entre as posições de sujeito com a forma-sujeito, as quais não comparecem transparentemente, mas por meio da análise da opacidade dos textos, mediante dispositivos teóricos. Nesse sentido, o gênero não é simplesmente uma imposição (a que se pode opor, como se soubéssemos exatamente o que este é), mas materialidade fluida, plástica, que conFORMA corpos, qualificandoos como "vida possível". Trata-se de um funcionamento que não pode ser localizado empiricamente, mas percebido em seus efeitos (abrindo possibilidades de serem outros pelo trabalho da compreensão, da leitura).

Com Butler (2003), propomos a performatividade como atividade repetitiva e citacional, mediada por normas que tornam um corpo viável, legível. A repetição refere-se a dois aspectos importantes: o efeito imaginário de que o sujeito está copiando um modelo (sobre "ser homem" ou "ser mulher", por exemplo) já existente; o fato de a insistência em "retomar" algo que já existe produzir efeito de duração, ou seja, de que algo existe porque resiste e persiste produzindo uma temporalidade mais ampla. O citacional refere-se a uma condição fundamental da performatividade: ela não ocorre isoladamente, mas em relação a outros discursos que se atravessam constantemente. Logo, ainda que o sujeito 
sofra e produza, pela repetição, supostos efeitos de masculinidade, a cada ato performativo os sentidos se deslocam, já que ocorre em tempos e espaços diferentes. Sendo assim, não se pode esquecer de algo fundamental: há um sujeito neste processo. Isso significa que não é possível a pura retomada de "modelos", já que há imbricação entre a memória e a atualidade, ocorrendo a partir de posições em relação a uma forma-sujeito capitalista e a processos de individuação pelo Estado (ORLANDI, 2017a). A performatividade constitui a enunciação do sujeito, produzindo como efeito a ilusão de ele ser autônomo e livre para escolher, quando, na verdade, a possibilidade do dizer já é habitada pelo assombro de poder ser outra, de produzir o que não se pretende, o que não se deseja. O sujeito performatiza porque interpreta, agindo na história porque inscreve-se no simbólico, crendo, muitas vezes, que faz "representação", "mimetização". Interpreta, logo, porque identificado à forma-sujeito histórica capitalista e sustentado por alguma possibilidade de "ser indivíduo" (ainda que "dissidente" ou segregado) pelo Estado. Pensamos, então, em uma performativização que produz gesto de interpretação ${ }^{4}$, o lugar de relação do sujeito com a língua (ORLANDI, 1996), afetado pela história e pelo ideológico.

$\mathrm{Na}$ perspectiva discursiva, podemos trazer para esta reflexão que toda descrição abre sobre a interpretação, colocando em jogo necessariamente o discurso-outro. Esse discurso-outro marca, no interior da materialidade da sequência, (...), a insistência do outro, como lei do espaço social e da memória histórica. No caso da ideologia, como sabemos, este efeito realiza a ilusão do sujeito como origem de si e dos sentidos que produz, efetivando a estrutura e o funcionamento da forma-sujeito histórica, a do capitalismo, que se sustente no jurídico, sob o modo de um sujeito de direitos e deveres, funcionando como sujeito autônomo e responsável (...). (ORLANDI, 2017a, p. 22-23)

Tomamos a liberdade, então, de acrescentar o seguinte à visada de Judith Butler por meio da interlocução com a Análise de Discurso: a materialidade dos corpos consiste na possibilidade de certo dizer, certa performatividade, poder comparecer em certas condições de produção e falhar. Não se trata de entender por que certo corpo e não outro comparece, mas de como isso se torna possível e, pela articulação

4. Vale lembrar que Pêcheux (1969) define o gesto como um ato simbólico que intervém no real, noção a partir da qual Orlandi desenvolve a noção de gesto de interpretação como uma intervenção no real do sentido. 
com Pêcheux, como funciona no uso feito da língua e da linguagem. Enunciar, portanto, é estar inscrito em uma filiação no interdiscurso ${ }^{5}$, o qual é irrepresentável, porque "na memória discursiva fala uma voz sem nome" (ORLANDI, 2017a, p. 17). Ou seja, o interdiscurso não é linear (porque não é memória que pode ser retomada teleogicamente, temporalmente) nem conjunto de dizeres interpretáveis palavra a palavra (mas palavras que falam com palavras). A performatividade, articulada com a perspectiva discursiva, não é fruto de aprendizagem e nem é consciente, ela é "contradição na singularidade" (ibidem), na qual o sujeito, performando, é performado. É constitutiva do efeito-sujeito a incompletude, assim como o equívoco é constitutivo dos efeitos de sentido, ambos afetados pelo real da língua e o real da história.

\section{LEITURA E COMPREENSÃO COMO TRABALHO NA LÍNGUA}

Entendemos que a compreensão (ORLANDI, 2012) surge como efeito de um gesto analítico (ORLANDI, 1996), já que é trabalho sobre o processo discursivo de significação. Nessa direção, não é possível trabalhar a compreensão desvinculada de ideologia: seja para analisar efeitos desta em funcionamento; seja porque o próprio gesto de leitura é materialmente produzido. Em outros termos, há uma divisão social do trabalho de leitura (não se é dado a ler da mesma forma dada a contradição entre as posições de sujeito que moldam os gestos de interpretação) e dadas as condições históricas das práticas de leitura. Logo, o equívoco (ORLANDI, 1996) entre língua e história é inevitável, já que a relação entre ambas não é linear, mas opaca, colocando os sentidos em deriva. É aí que o analista deve se posicionar para ler, mobilizando um dispositivo teórico e analítico de interpretação e se inscrevendo em uma história de gestos de leitura já legitimados.

Então, não há construção de um caminho que visa a resgatar o conteúdo que determinado texto "possui". Diferentemente, tomamos, a partir da Análise de Discurso inaugurada por Michel Pêcheux (1998), o texto como unidade de análise, cuja significação é possível por um trabalho de um sujeito leitor, cuja posição possibilita a construção de leituras. Por um lado, o texto não possui sentido "em si"; por outro, não quer dizer que o sentido possa ser qualquer um. Ao contrário, é

5. O interdiscurso é o todo complexo à dominante das formações discursivas, cujas bordas provisórias e porosas se movimentam ao sabor da história. Ele atua de modo que é "próprio de toda formação discursiva dissimular, na transparência do sentido que nela se forma, a objetividade material contraditória do interdiscurso, que determina essa formação discursiva como tal, objetividade material essa que reside no fato de que "algo fala" (ça parle) sempre "antes, em outro lugar e independentemente", isto é, sob a dominação do complexo das formações ideológicas" (PÊCHEUX, 1995, p. 162). Entre outros termos, o interdiscurso sofre efeito de esquecimento para que o sujeito possa fazer, acreditando que é dono de seu dizer e que tudo "possui um nome". 
justamente o fato de ele poder funcionar de uma maneira e não de outra, em determinadas condições de produção, algo que deve ser tomado pelo analista como fundamental para a compreensão. Trata-se de uma prática - a compreensão ${ }^{6}$ - que se dá na relação entre simbólico e imaginário, dado que a legibilidade não se dá "palavra a palavra", mas na constituição de sentidos entre intradiscurso e interdiscurso. Nos termos de Pêcheux:

uma palavra, uma expressão ou uma proposição não tem um sentido que lhe seria "próprio", vinculado a sua literalidade. Ao contrário, seu sentido se constitui em cada formação discursiva, nas relações que tais palavras, expressões ou proposições mantêm com outras palavras, expressões e proposições da mesma formação discursiva. De modo correlato, se se admite que as mesmas palavras, expressões e proposições mudam de sentido ao passar de uma formação discursiva a uma outra, é necessário também admitir que palavras, expressões e proposições literalmente diferentes podem, no interior de uma formação discursiva dada, "ter o mesmo sentido". (PÊCHEUX, 1998, p. 147).

No processo de redação deste artigo, a relação com o sentido e a interpretação que viemos apresentando iniciou-se pelo contato com as provocações de Judith Butler sobre gênero e linguagem. Só depois, passou-se ao contato com as propostas teóricas e políticas da Análise de Discurso de Michel Pêcheux: o que ajuda a desenvolver não uma linha de continuidade entre ambos, mas a construção de um caminho outro de compreensão sobre as (im)possibilidades de o sentido acontecer. Portanto, acreditamos que a perspectiva assumida pelos textos filosóficos de Butler pode ser lida em articulação com a teoria discursiva desenvolvida a partir de Pêcheux, produzindo, então, uma posição outra, de entremeio, entre as duas grandes obras.

\title{
UM CORPO TRANSFORMA?
}

\author{
Entre a oração e a ereção \\ Ora são, ora não são \\ Unção \\ Bênção
}

\footnotetext{
6. Vale lembrar que, para Orlandi (2012), "compreensão" é usada, na perspectiva discursiva assumida pela autora, para corroborar um processo de leitura não pautada no resgate de conteúdos, mas na elaboração de "sentidos outros" para os textos, considerando que eles significam não de maneira universal, mas submetidos a condições de produção de enunciação e de leitura.
} 


\section{Sem nação}

Mesmo que não nasçam

Mas vivem e vivem

E vem

Se homens

Se amam

Ciúmes

Se hímen

Se unem

(DA QUEBRADA, Linn, 2020)

As obras selecionadas para este artigo foram, inicialmente, apresentadas pela própria Alice Yura, durante a organização do volume Nós (em) Butler (BIZIAK, 2020). Tratava-se de um momento de seleção de imagens, feita em diálogo com a artista, que iriam compor esta publicação. Durante o trabalho de organização do referido volume, as três obras despertaram o olhar para "a imagem em sua potência de captura simbólica" (LAGAZZI, p. 5890, 2021), dando "visibilidade à partição do social" (ibidem, p. 5892) no que diz respeito a possíveis efeitos sobre/ de abjeção. Com isso, não foi possível escolher uma somente, e todas compuseram a capa (BIZIAK, 2020). As figuras 01 e 03 fazem parte, também, de uma entrevista com Alice Yura (PERFORMATUS, 2019). Além disso, a figura 03 é fotografia de Vânia Jucá de uma performance realizada por Yura em Campo Grande, Mato Grosso do Sul, no ano de 2014 (ibidem). Já a figura 02 corresponde a trabalho presente em arquivo pessoal de Alice Yura e disponibilizado no momento de elaboração do livro já citado (BIZIAK, 2020). Dessa forma, as obras analisadas proporcionaram um trabalho de leitura que nos levou à interrogação sobre o funcionamento da abjeção em perspectiva discursiva. Ou seja, uma pergunta principal nos guiou: seria a abjeção específica da/na construção de alguns corpos ou constitutiva de todos eles? Com essa questão, seguimos. 
Com o nome de 16:26:34, tomamos a primeira obra de Alice Yura.

- Figura 01: 16:26:34 (2019) -

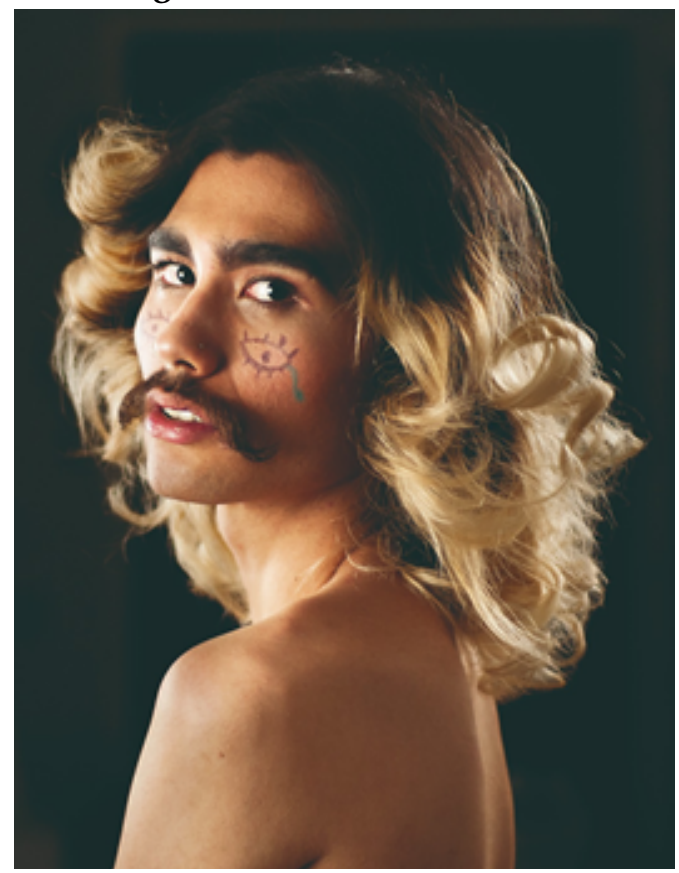

Fonte: Performatus: https://performatus.com.br/entrevistas/alice-yura

Em um contato inicial com ela, citamos Didi-Huberman:

$\mathrm{O}$ ato de ver não é o ato de uma máquina de perceber o real enquanto composto de evidências tautológicas. O ato de dar a ver não é o ato de dar evidências visíveis a pares de olhos que se apoderam unilateralmente do 'dom visual' para se satisfazer unilateralmente com ele. Dar a ver é sempre inquietar o ver, em seu ato, em seu sujeito. Ver é sempre uma operação de sujeito, portanto uma operação fendida, inquieta, agitada, aberta. Entre aquele que olha e aquilo que é olhado. (1998, p. 77)

Trata-se de uma relação de olhares cujo caráter material não pode ser colocado em segundo plano. Não se trata de olhos sem corpo, mas que constituem, formam uma corporeidade que emerge à leitura como possível. O olhar que produz gesto de leitura o faz a partir de relações institucionais sobre arte, corpo, vida, gênero. Isso ocorre por 
uma mistura, aparentemente paradoxal, entre elementos que podem ser lidos como "masculinos" e "femininos", por conta da memória que os sustenta como sentidos que parecem existir em outro lugar, já-dito. Além disso, a postura assumida pelo corpo remete a outra ressonância: em espaço diverso, algo semelhante parece que pôde ocorrer. Recortamos, especialmente, a obra Moça do brinco de pérola (1665), pintada pelo holandês Johannes Vermeer. Não se trata de haver alguma suposta "intertextualidade proposital", algo do plano do conteúdo e do sujeito volitivo. Mas, ao destacar as duas obras e as colocar em relação, há algo que retorna como já-feito e novo, ao mesmo tempo, inscrevendo lugar para o corpo da obra de Yura no simbólico e no imaginário. Não só a postura assumida pelas duas personagens das obras é muito semelhante, outros pontos chamam a atenção: o peso do olhar, quase central na organização do espaço; o jogo entre luz e escuridão (entre frente e fundo, velar e revelar), algo costumeiramente associado na história da arte com o chamado "estilo barroco". Como diferença, a nudez assumida na obra de Alice Yura.

Pelo exercício anterior, a memória é rasgada, costurada e posta em ato como acontecimento. Temporalidades encontram-se para significar identidades e diferenças. No espaço entre olhar da personagem e do expectador, um dos aspectos fundamentais da performatividade de corpos gendrados: o sujeito e o sentido emergem juntos. Não há "feminino", por exemplo, anterior à leitura da obra: a de Yura não é lida da mesma maneira que antes da possibilidade de relação com a de Vermeer e nem se esgota aí. Da mesma maneira, agora, a compreensão da pintura do holandês não é mais possível de ser outra, uma vez que relacionada à de Yura. Entendemos, então, por isso, a memória transformando-se não em alguma cronologia, mas na descontinuidade das relações que podem ser estabelecidas por meio das posições-sujeito de leitura. Além disso, a própria performatividade é acontecimento discursivo ${ }^{7}$ que ocorre simultaneamente à leitura, seja para poder enunciar ou compreender: dizemos isso à medida em que outras filiações de sentido são convocadas à leitura do hegemonicamente estabelecido sobre gêneros. Não se trata de "explicar" uma obra a partir da outra, mas de analisar como as formas, por outro lado, para que haja algum sentido, não podem ser qualquer uma.

Neste intervalo entre olhar e ser olhado, o sentido sempre pode ser outro. Por ação do interdiscurso, há enunciados que podem produzir efeitos de feminilidade, outros de masculinidades; mas, reunidos, respeito entre a articulação do que poderia estar inscrito e não está (persistindo em ausência) com a atualização. 
tais possibilidades deslizam e clamam por significação no novo acontecimento que é esta primeira obra de Alice Yura:

Nesta perspectiva, o interdiscurso, longe de ser efeito integrador da discursividade torna-se desde então seu princípio de funcionamento: é porque os elementos da sequência textual, funcionando em uma formação discursiva dada, podem ser importados (meta-forizados) de uma sequência pertencente a uma outra formação discursiva que as referências discursivas podem se construir e se deslocar historicamente. (PÊCHEUX, 2015, p. 158)

Por isso, lemos o corpo (em sua pose, recortada em relação à memória discursiva) como metáfora, deslocamento: a imagem substitui algo que não pode estar lá (outras referências discursivas) e que só pode ser assim (uma vez que, sem aquelas, todavia, não há como significar). Com isso, passamos a sugerir que a performatividade é esta relação dos corpos, dos gêneros e das vidas que só pode ser lida entre ser-outra e não-poder-ser-outra: não há fechamento nem da legibilidade e nem da identificação construída na/pela enunciação.

Ainda que o corpo lido fosse (re)conhecido, há um resto que atua e indica a falha do simbólico: este corpo sempre pode ser diverso. Este é efeito da norma, da regulação institucional do Estado: funciona como assujeitamento e como resistência, dado que como nos lembra Pêcheux (1975) "não há ritual sem falha". Isso, a nosso ver, dialoga com Butler (2007), quando afirma que todo sujeito é constituído por uma força de exclusão, pelo "fundante repúdio" do que não pode ser dito porque é impossível dizer tudo. Soma-se que não se diz o que se quer, mas as formas dadas pela ação material da ideologia na língua e na história. Neste corpo que comparece a nos olhar, na obra nomeada como 16:26:34 (2019), há um "isso" dos gêneros que permanece vazio, sem referência. Há "feminino", mas é outro; há "masculino", mas é outro; há "corpo", mas é outro. O "isso" que resta é importantíssimo (mais do que qualquer possibilidade de referência discursiva) porque é o que movimenta sentidos na história. Se há efeitos de interrogação do olhar corporificado em relação ao leitor, é somente pela via da materialidade do intervalo em que se realiza a leitura: formulação e leitura são reguladas (ORLANDI, 2012, p. 15). A partir daí, começamos a (re)pensar a abjeção, o abjeto.

Pensando com Orlandi, (2012, p. 135-137), leitura é participação no processo sócio-histórico de produção de sentidos, feita a partir 
de um lugar social e em certa direção histórica. Sendo assim, somos constituídos como leitores institucionalmente, em um confronto de forças políticas e ideológicas. Sentido é disputa que ocorre na luta de classes. Logo, não se possui, é produzido, posto em funcionamento por determinada materialidade que não é fruto da livre escolha do sujeito. Portanto, não há possibilidade de ingressar nos atos simbólicos da história sem ser pela interpretação: esta, por sua vez, não se dá de forma simétrica entre os sujeitos (a não ser como efeito ideológico) porque as identificações dos sujeitos inscritos em posições não ocorrem das mesmas maneiras, como se fossem lugares de encaixe perfeitos e desdejá conhecidos. Nessa direção, a obra de Yura é uma tomada necessária de posição em relação à memória para poder significar em formações discursivas que são institucionalmente legitimadas, como a da arte. Por esta via, tanto leitura quanto enunciação não podem ser desvinculadas de uma formação social, e, nesta o sujeito se apropria do repetível e intervêm nele. Novamente, nesta relação entre enunciação e leitura, obra (texto como unidade de análise) e leitor, algo resta, incomodando e possibilitando o esgarçamento dos sentidos.

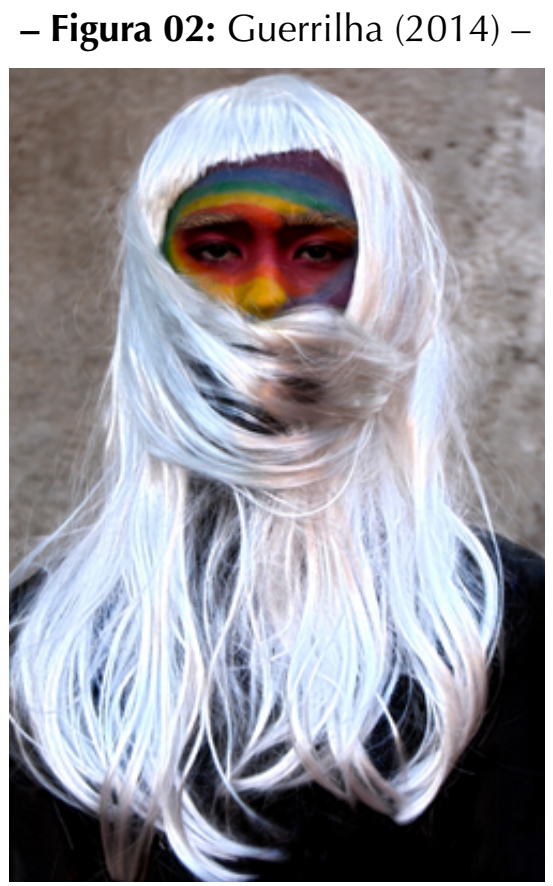

Fonte: arquivo pessoal da artista

Mais uma vez, o olhar como materialidade central à obra: ele não 
pode ser tomado como nenhuma obviedade, por exemplo. Os cabelos, longos, tamponam a boca, um dos lugares privilegiados de enunciação verbal. No que sobra, arco-íris. No que circunda, preto, branco e bege. Bege ou "nude", dependendo do recorte na memória, criando relação discursiva. As cores, em sua materialidade, não escapam à divisão social de leitura. É justamente por "nude", "bege" poder ser algo e não poder ser, ao mesmo tempo, que "algo" insiste sem poder ser simbolizado, sem inscrição no imaginário.

Cabelos brancos, vestimenta preta, fundo bege, "nude". Ao centro, o olhar direcionado ao leitor em uma fresta de corpo, tomado por cores mais vibrantes (e comumente interpretadas como do movimento LGBTQIAP+), destoando do restante da obra. Novamente, pelo recurso da relação entre "materialidades significantes imbricadas na composição de um texto" (LAGAZZI, 2019) e interdiscurso, a memória comparece pela via da possibilidade de leitura do arco-íris como inscrição simbólica de um conjunto heterogêneo de ações e corpos, contraditoriamente, possíveis de serem interpelados pelas paráfrases: Movimento LGBTQ, Movimento Gay, Queer, Orgulho Gay etc. Optar por um nome é silenciar os demais, sem possibilidade de escapar de certa homogeneização. Logo, a obra confronta duas materialidades que, aqui, funcionam como se fossem distintas: as materialidades do bege/nude, do branco e das cores vibrantes/arco-íris. De início, recortando memórias que ressoam como diferentes. Enquanto a obra anterior faz funcionar cores, luzes e sombras de forma a abrir determinadas possibilidades de leitura com/ pela memória; em Guerrilha, analisamos outro procedimento.

Um resto em comum a interrogar no intervalo entre obra e leitor: o olhar, "colorido". Este "colorido" que pode, corporificado, circular e produzir significações diversas é índice importante de um processo que Berenice Bento (2017, p. 81) chama de "embaralhar fronteiras": "O corpo é utilizado como manifesto, como um locus de produção de contradiscursos, de reinscrituras à ordem de gênero. As citações são descontextualizadas de um referencial biológico, são masculinidades sem homens". Se é possível uma "descontextualização", é por ação das condições de produção, mediante e a partir das quais são possíveis recortes de memória.

Butler (2015b) apresenta a abjeção a partir do problema específico da exclusão de certos corpos como paradigma para se pensar gênero. Assim, para a filósofa, o abjeto corresponderia àquilo que não pode e não deve ser visto, corpos execrados que não teriam representabilidade 
e cuja materialidade é marginalizada, já que apontaria para fissuras no imaginário hegemônico sobre as vidas possíveis. No entanto, entendemos que a abjeção/o abjeto não se confunde com isso que Butler propõe, já que responde a uma impossibilidade do enquadramento. Ser enunciado como "vida não possível", "de corpo não reconhecido/reconhecível", paradoxalmente, já é uma possibilidade de simbolização, ainda que recalcado, atuando como um saber esquecido que, no movimento descontínuo da história, não deixa de produzir equívoco (e falha no simbólico). Portanto, não compreendemos (respaldados pelo gesto de leitura que tentamos elaborar aqui) o abjeto como referência para determinados corpos ou vidas ou gêneros, mas como um processo que não acaba e que constitui a própria possibilidade de uma corporeidade vir a ser simbolizada/significada. Logo, a abjeção não seria a marca de alguns corpos, mas de todos os corpos, já que eles sempre implicam um impossível do sentido. Este, justamente, permite os deslocamentos dos processos de significação sobre as vidas na história.

Nas duas obras anteriormente apresentadas, há a constituição e a formulação de uma possibilidade identitária, uma narratividade do corpo (ORLANDI, 2017b, p. 79), memória encarnada. Trata-se de acontecimento discursivo e político que atinge o corpo do sujeito em seu processo de individuação. Não há outra ferramenta para a cirurgia de linguagem (as cores, os volumes, as formas etc.) sobre o corpo com a finalidade de surgir como um sujeito que não sejam os pré-construídos, recortes rememoráveis que significam a partir de uma determinada condição de produção. As tramas da memória podem ser desfiadas, rasgadas, costuradas, customizadas, mas não destruídas: caso contrário, não há sujeito nem sentido. Mesmo ascender como corpo indesejável inclui alguma inscrição no simbólico, alguma âncora na deriva do imaginário. A abjeção, por sua vez, é funcionamento de outra ordem, mas não excluída das corporeidades em suas enunciações e legibilidades. Em outros termos, discursivamente, a abjeção não corresponde a uma "ausência de representação" ou a simplesmente a exclusão de alguns corpos. Diferentemente disso, o abjeto é condição do que se apresenta como legível em determinadas condições de produção: é justamente a impossibilidade de que, por exemplo, um corpo ou uma posição de sujeito faça Um, seja algo estável e plenamente determinado. A possibilidade de todo corpo ser compreendido e performativizado como outro (a abjeção) é necessariamente recalcada para que haja princípio de unidade de vidas e corpos para a leitura do outro. 
A individuação do sujeito em relação ao Estado envolve a textualização do corpo (ORLANDI, 2017b, p. 75). Este é dito (com a ilusão de falar a "si próprio") no funcionamento do efeito metafórico, "o fato de que todo enunciado é constituído por ponto de deriva que podem deslizar produzindo um sentido outro. Ou seja, a memória constitutiva é uma rede de filiações de sentidos que podem e devem se deslocar, portanto, uma rede em que se produz o mesmo e a diferença" (ibidem, grifo da autora). A corporeidade, então, produz efeito de unidade e possibilidade da polissemia. Dessa maneira, pela interpelação (sempre precária) pela forma-sujeito de direito, uma ilusão de estabilidade (ser identificado/reconhecido em relação a um ou outro sexo) é praticada como sentido: no entanto, é seu caráter material que faz com que seja impossível de tudo ser dito, simbolizado. A existência de intervalo entre olhar e ser olhado, entre enunciar e ser interpretado, instaura a materialidade da distância e do encontro contingente (ALTHUSSER, 2005) que faz os sentidos ressoarem e silenciarem, ao mesmo tempo. E, por não se escapar e por cada posição sujeito sofrer/corporificar/ encarnar efeitos diversos disso, o estranhamento é sempre algo possível. A produção histórica da sensação de não pertencimento, de não se conseguir ser/dizer habitada nas bordas pelos rastros-enunciados.

Em entrevista de 2002 (PRINS \& MEIJER), Judith Butler insistentemente é convocada a revisitar o que poderia ser tomado como abjeto: "A abjeção de certos tipos de corpos, sua inaceitabilidade por códigos de inteligibilidade, manifesta-se em políticas e na política, e viver com um tal corpo no mundo é viver nas regiões sombrias da ontologia" (ibidem, p. 157, grifo meu). A mencionada "inaceitabilidade", entendemos, não pode ser tomada como algo resultado de uma vontade, individual ou coletiva, mas como condição que sustenta todo devir de corporeidades. Todo sujeito, em sua sustentação, é habitado por algo que não pode ser simbolizado, que não aceita códigos. Portanto, uma maneira discursivamente produzida para fazer surgir posições de sujeito, sempre valoradas, é tomar algumas destas, imaginariamente, como matriz de identificação, como se fosse possível transformar a borda da falta constitutiva em um novo centro. Enquanto isso, outras formas de individuação continuam sendo possíveis, discursivamente, mas a partir de relações referenciais, criadas na história e pelas lutas de classes, que produzem marcas lidas como "subalternização", "anormalidade", "erro a ser corrigido", "doença a ser curada", "pecado" etc. Este deslizamento de significantes não constitui a abjeção, diferentemente: é ela, a (im) 
possbilidade de presença materialmente excluída, sempre em relação de dentro/fora, que é condição de que os sentidos e os sujeitos sejam corpos precários e sempre assombrados/animados pelo chamado a serem outros nos acontecimentos discursivos. Uma das formas históricas de propor movimento a "isso" é a performance artística.

- Figura 03: Meu nome é Neusa, venho em paz... (2019) -

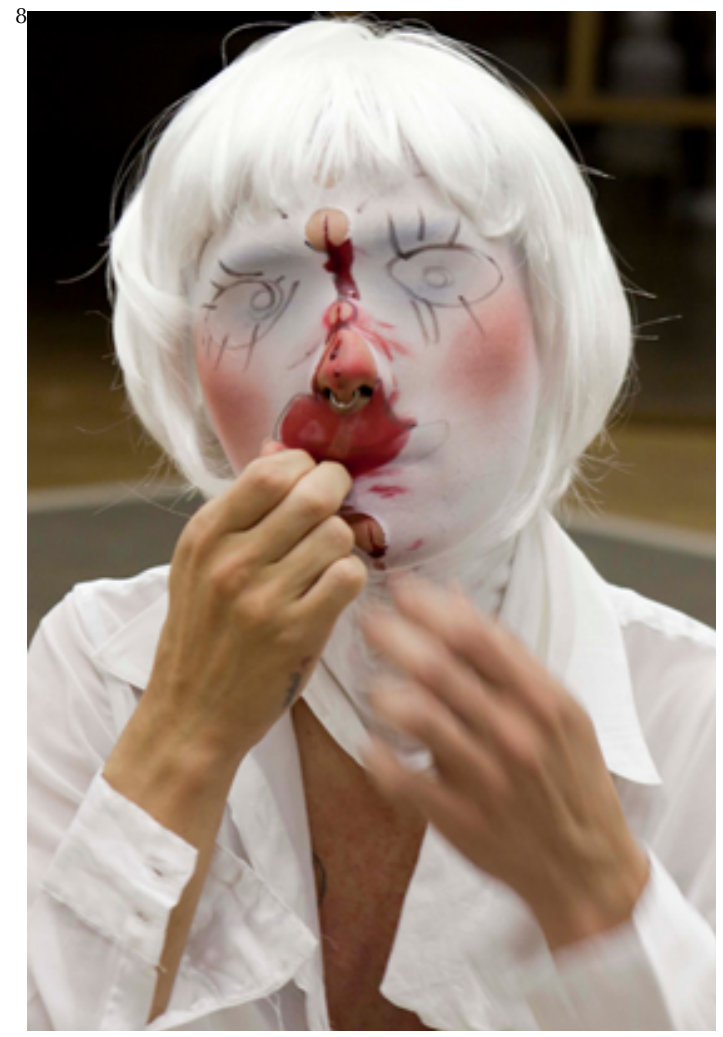

Fonte: Performatus: <https://performatus.com.br/entrevistas/alice-yura/>

Ao centro, novamente, olhar(es): o desenho, substantivo; e a atividade, verbo. O olhar está oculto por um desenho de olhos, que se sobrepõem e apagam ao mesmo tempo o olhar de um sujeito. Esse desenho, para ser interpretado como olhar, precisa ser tomado na relação com o corpo que o próprio desenho oculta. Fundo duplo, efeitos entre presença (do desenho), ausência (dos olhos), presença (de um corpo),

8. A performance pode ser apreciada em um formato vídeo também: YURA, Alice. Meu nome é Neusa, venho em

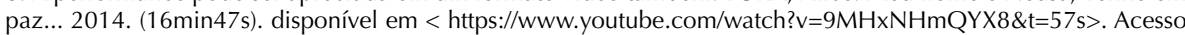
em 13 de maio de 2020. 
ausência (de um olhar desse corpo). Só há olhar por antecipação a partir do olhar do espectador que projeta imaginariamente o olhar que o desenho oculta. Um rasgo é construído pelas mãos do mesmo corpo que encarna a narratividade ${ }^{9}$ de olhos sem pele, olhos plásticos e de tinta. As cores, predomínio de branco, atravessado de/por vermelho. Nesse deslizamento de significantes e de efeitos de sentido como possível, permanente e inconcluso, um jogo entre superfície rasgada e conteúdo velado e, em parte, antecipado pelos desenhos sobre a "pele" plástica, branca, entre índices de paz (corpo que vive) e de ausência de vida (corpo morto). Um corpo plástico e elástico, mas sem vida; abaixo, algo guardado, rastros de pele que emergem na borda entre aparecer e esconder. Na performance de Alice Yura, certo efeito de unidade é alternância, intervalo, de não acabar entre corporeidades: uma, rompida, de matéria morta; outra, em um limite de nascer/morrer ainda incompleto. Na cena, o olhar se direciona ao possível leitor, mas substituído pela "representação" que, necessariamente, falha no reconhecimento, mediada pelo rasgo e pela mão que pode mostrar alguma alteridade subterrânea-crisálida. A narratividade funciona guardando um corpo dentro do outro e ganhando sentidos díspares na história: o corpo que morre; o corpo ciborgue; o corpo que se constrói, o corpo que sofre; o corpo que vive; o corpo mentira; o corpo revelador; o corpo que constrói a si; o corpo que destrói a si; o corpo subalterno; o corpo resistente; enfim.

Temos chamado a atenção para a centralidade do olhar nas obras das figuras 01 e 02 , no recorte presente na figura 03 e para como ele se move nas cenas, ao ponto de, em Meu nome é Neusa, venho em paz..., dividirem o protagonismo com as mãos, ato de rasgar, revelar. Entre a textualização destes olhares corporificados e a posição do leitor, funciona o processo interpretativo que funciona entre o sujeito com o outro no discurso (SALLES, 2018, p. 102):

Nessa direção, é possível dizer que o performer não produz uma performance como um objeto a mais dentre outros; o performer, pelo seu olhar, coloca o expectador em cena, captura-o. Isso acontece pelo olhar e, em especial, pelo corpo. Será? Diria, sim e não, pois nem todos são capturados. Ou melhor, cada um que participa

9. Orlandi (2017: 30), o conceito de narratividade é definido como "a maneira pela qual uma memória se diz em processos identitários, apoiados em modos de individuação do sujeito, afirmando/vinculando seu pertencimento a espaços de interpretação determinados". 
da performance é capturado de modo diferente. (ibidem, grifos do autor)

Os participantes da performance, em posições diferentes (artista e espectador), são capturados diferentemente porque há possibilidade da abjeção sempre. Ou seja, a abjeção funciona discursivamente não somente a respeito de um corpo e de processos de identificação, mas como indelével em quaisquer formulações da corporeidade. Há possibilidade não contada no corpo, mas que atua produzindo borda para este, garantindo que haja efeitos e, ao mesmo tempo, os colocando em risco. Com a leitura das obras de Alice Yura, entendemos que toda textualização é lugar da metáfora (como já mencionei anteriormente); no entanto, nestas imagens, o irrepresentável constitui a própria formulação como ausência que não se quer contornar, mas esgarçar como inscrição material do abjeto que não pode ser erradicado, ainda que possa ser politicamente reforçado em certos procedimentos da língua e da imagem na formulação das corporeidades. Logo, o abjeto acontece. Na foto, recorte da performance, em suas condições de produção, o abjeto é a garantia de entrada em um lugar-para-sempre-outro da memória.

Lendo Yura, distinguir performance (uma forma materialmente construída para que haja enunciação) e performatividade (da qual nenhum sujeito escapa) é algo fundamental. Compreendemos a performatividade do corpo em performance como acontecimento específico, institucionalizado, e que diz de miragens de presença, escancarando a irrefutabilidade de uma falta que nos conduz a toda possibilidade de contato com o outro, em deriva, processo-princípio do real. No jogo de horror e incômodo com o olhar do outro (jogo de avesso com a abertura para o vivível), a abjeção é a experiência de resto, de inominável, que não se inscreve no simbólico. Este resto, o abjeto, é o que, discursivamente, entendemos como o impossível de contornar: seja para fugir, seja para controlar, seja para garantir corpos/corporeidades que façam sentido.

\section{ABJEÇÃO E DISCURSO: RELAÇÃO DE NÃO ACABAR}

A quem costumeiramente ama

A mente ama também

Não queimem as bruxas

Mas que amém as bixas

Mas que amém 
Que amém

Clamem

Que amém

Que amém as travas também

Amém ${ }^{10}$

Conforme visto, Butler (2002 e 2003) conceitua o abjeto como "característica" de alguns corpos, alguns gêneros e algumas vidas em especial. Por nosso turno e por meio do gesto de leitura construído com as performances de Alice Yura, percebemos a dificuldade de aceitar este entendimento. Dificilmente, os corpos analisados não seriam lidos como abjetos. Isso funciona como constituição no imaginário e de formulação no simbólico: algo possibilitado pela relação com enunciados que são tomados como se já significassem em outro lugar (cabelos, poses, bigodes, cores etc). Em outros termos, se há enquadramento, acontece efeito de sentido, disponível aos usos políticos próprios da divisão da apreensão das realidades pelas instituições. O abjeto/a abjeção é constituinte do acontecimento, mas em outra ordem: a possibilidade de abertura do sentido no/dos corpos para qualquer outro, de forma que desliza e acontece mediante condições materiais de produção.

No gesto de interpretação construído com base nas três obras de Alice Yura, a formulação permite um efeito de sentido, também, sobre "desvio": corpos que, enunciados, materialmente provocam dizeres sobre o que pode ser uma corporeidade. Nas imagens, a cena põe, inevitavelmente, o acontecimento discursivo do corpo como precariedade: passível de desmontagem, recriação, fazer-outro; mas, também, com indicativos de formas de sofrimento, morte, violência. Aí, fazemos intervir a proposição de Judith Butler:

Reconhecer a violência não garante, de modo algum, uma política de não violência. Mas o que pode perfeitamente fazer diferença é considerar a vida precária e, portanto, também a condição de violável uma condição generalizada, em vez de uma maneira diferencial de marcar uma identidade cultural, isto é, como um traço recorrente ou atemporal de um sujeito cultural que é perseguido ou violado por definição e independentemente da circunstância histórica. (2015b, p. 250-251)

Precariedade, condição da qual nenhuma performatividade 10. Ibidem. 
escapa, nenhuma vida se livra (todo corpo pode ser desfeito, inclusive pela morte). Condição precária, uso político que pode ser realizado da precariedade. Em Yura $(2014 ; 2019)$, vemos a precariedade e a condição precária como materialmente possibilitadas como efeitos. A performance artística, modo específico de formulação e circulação, permite a exacerbação da montagem como elemento constitutivo do corpo em cena, objeto e instrumento da obra. Assim, pela ênfase nas formulações (partes do corpo, cores, materiais sintéticos) que desestabilizam o imaginário discursivo sobre "linearidade, coerência, norma, regra", a precariedade ganha espessura material, agindo na história das significações sobre corporeidades, gêneros e vidas. Ao mesmo passo, marca-se, inevitavelmente, algo da fragilidade que, "plástica", pode ser rasgada, emergindo a memória saturada de vermelho.

Portanto, pelo caminho de leitura que estamos tentando construir, aqui, a condição precária (maximização da vulnerabilidade a que toda vida, finita que é, está exposta) funciona e deve ser lida ao nível da posição assumida pela enunciação diante da partilha do sensível (RANCIÉRE, 2009), ato eminentemente político. Ao mesmo tempo, seu caráter metafórico de poder funcionar e, também, de ser colocado a funcionar em outro lugar ocorre no e por causa do que não cansa de não poder se escrever/inscrever, ser simbolizado. O abjeto não deixa de comparecer, de insistir como "isso" inominável que coloca corpos à deriva, já que marca e possibilita a fundação destes. Não se trata da ordem do recalque ${ }^{11}$, do corpo generificado e/ou da vida reprimidos, mas do abjeto que não deixa de funcionar, abrindo furos, brechas no simbólico (indicando o caráter plástico, artificial e precário de toda formulação/identificação da corporeidade, fazendo irromper, por baixo, algo que se esconde e se mostra, algo que é sem ser ainda, à moda $\mathrm{Meu}$ nome é Neusa, venho em paz..).

Propomos, então, a abjeção como trabalho de não acabar das corporeidades sem rosto e sem nome, que não cessa de não se inscrever nos movimentos da história, na materialidade da ideologia e da linguagem. O abjeto não é sinônimo do silêncio ou do non-sens, mas o resto de toda formulação da corporeidade que não se inscreve no simbólico. O abjeto como um trabalho material de substituição permanente de efeitos de corporeidade por bordeamentos ao furo, à falta (daí, o caráter temporário de toda inscrição, de toda simbolização):

11. Indicamos, aqui, homologamente, o desenvolvido por Lacan a respeito desta negação que não é recalcamento nem expulsão (o que já seriam possibilidades de inscrição simbólica, de lugar possível a ocupar). Diferentemente, trata-se de um retorno ao real pela abolição do significante no vazio. 
"isso" da performatividade que falha (precária que é) e é tão importante na performance artística e, concomitantemente, índice de horror/ estranhamento nas formas hegemônicas de individuação possibilitadas pelo Estado em relação à forma-sujeito capitalista. Nesse sentido, não há corpo que não porte abjeção (da ordem do real) e precariedade (da ordem do simbólico e do imaginário) ${ }^{12}$. Pela distribuição desigual de luto público (BUTLER, 2014), a condição precária, materialmente produzida na história, emerge na enunciação e no acontecimento. Logo, na forma de emergência dos corpos habita a possibilidade de que vidas sejam outras, que tenham outros problemas e encontrem novas soluções.

\section{REFERÊNCIAS BIBLIOGRÁFICAS}

ALTHUSSER, Louis. De O capital à filosofia de Marx. In: ALTHUSSER, Louis et al. Ler o Capital. Rio de Janeiro: Zahar, 1979.

. A corrente subterrânea do materialismo do encontro. Crítica Marxista, Rio de Janeiro, Revan, n.20, 2005, p.9-48.

Sobre a reprodução. 2. ed. Petrópolis: Vozes, 2008.

BENTO, Berenice. A reinvenção do corpo: sexualidade e gênero na experiência transexual. Salvador: Devires, 2017.

BIZIAK, Jacob dos Santos (org.). Nós (em) Butler. Rio de Janeiro: Ape'ku Editora, 2020.

BUTLER, Judith. "Fundamentos contingentes: o feminismo e a questão do pósmodernismo". Cadernos Pagu, n. 11, p. 11-42, 1998.

. Cuerpos que importan: sobre los limites materiales y discursivos del "sexo". Buenos Aires: Paidós, 2002.

Problemas de gênero: feminismo e subversão da identidade. Rio de Janeiro: Civilização Brasileira, 2003.

Corpos que pesam: sobre os limites discursivos do "sexo". In: LOURO,

Guacira Lopes (org.). O corpo educado: pedagogias da sexualidade. Trad. por Tomaz Tadeu da Silva. 2a ed. Belo Horizonte: Autêntica, 2007.

O Clamor de Antígona: Parentesco entre a Vida e a Morte. Editora da UFSC, 2014.

Relatar a si mesmo. Crítica da violência ética. Belo Horizonte: Autêntica, 2015a.

Quadros de guerra: quando a vida é passível de luto?. Rio de Janeiro: Civilização

12. Pelo trabalho de leitura, distinguimos, então, condição precária e abjeção/abjeto: que, ao nosso ver, em alguns pontos da obra de Butler, acabam funcionando como sinônimos. No entanto, no nível de análise da compreensão de funcionamento da língua, de forma interessante, podem ser diferenciados como ordens distintas. 
Brasileira, 2015b.

A vida psíquica do poder: teorias da sujeição. Belo Horizonte: Autêntica, 2017. ;SPIVAK, Gayatri C. Quem canta o Estado-nação? - língua, política, pertencimento. Brasília: EDUNB, 2018.

DA QUEBRADA, Linn. Oração. Letras, 2020. Disponível em: https://www.letras.mus.br/ mc-linn-da-quebrada/oracao/. Acesso em: 11 de maio de 2020.

DIDI-HUBERMAN, Georges. O que vemos, o que nos olha. São Paulo: Editora 34, 1998, p.77.

ENTREVISTA com Alice Yura. Performatus, 2019. Disponível em: https://performatus.net/ entrevistas/alice-yura/. Acesso em: 11 de maio de 2020.

HENRY, Paul. Os fundamentos teóricos da "Análise Automática do Discurso" de Michel Pêcheux. Tradução de Bethania Mariani. In: GADET, Françoise; HAK, Tony. (orgs.). Por uma análise automática do discurso: uma introdução à obra de Michel Pêcheux. 2 ed. Campinas: Unicamp, 1993, p. 13-38.

LACAN, J. O seminário, livro 3: as psicoses (1955-1956). Rio de Janeiro: Zahar, 2010.

LAGAZZI, Suzy. Trajetos do sujeito na composição fílmica. In: Flores, G., Gallo, S., Lagazzi, S., Neckel, N., Pfeiffer, C., Zoppi-Fontana, M. (orgs.). Análise de Discurso em Rede: Cultura e Mídia - volume 3. Campinas: Pontes, p.23-39, 2017.

. A imagem em sua potência de captura simbólica. Fórum Linguístico, v. 18, n. especial, p. 5890-5902, 2021. Disponível em https://periodicos.ufsc.br/index.php/forum/ article/view/79657 Acesso em 07 de outubro de 2021.

ORLANDI, Eni Pulcinelli. Interpretação: autoria, leitura e efeitos do trabalho simbólico. Petrópolis: Vozes, 1996.

Discurso e Leitura. Cortez: São Paulo, 2012.

Ideologia e inconsciente. In: Eu, Tu, Ele: discurso e real da história. Campinas: Pontes, 2017a.

Um corpo migrante. In: Eu, Tu, Ele: discurso e real da história. Campinas: Pontes, $2017 \mathrm{~b}$.

PÊCHEUX, Michel. Semântica e discurso. Uma crítica à afirmação do óbvio. Tradução Eni Pulcinelli Orlandi [et al.] Campinas: Editora da Unicamp, 1998.

PÊCHEUX, M. O discurso: estrutura ou acontecimento. Campinas: Pontes Editores, 2006. Metáfora e Interdiscurso. In: ORLANDI, Eni Puccinelli. (Org.). Análise de Discurso: Michel Pêcheux. Campinas: Editora Pontes, 2015.

PRINS, Baukje, MEIJER, Irene Costera. Como os corpos se tornam matéria: entrevista com 
Judith Butler. In: Revista Estudos Feministas. Volume 10, número 1, Florianópolis, janeiro de 2002, pp. 155-167.

RANCIÉRE, Jacques. A partilha do sensível: estética e política. São Paulo: Editora 34, 2009.

RODRIGUES, Carla. Como a marca masculina poderia ser anterior à diferença sexual?. In: GARCIA, D., BIZIAK, J. SOUSA, L. Do cárcere à invenção: gêneros sexuais na contemporaneidade. São Carlos: Pedro e João, 2017.

SAFATLE, Vladimir. Posfácio - Dos problemas de gênero a uma teoria da despossessão necessária: ética, política e reconhecimento com Judith Butler. In: BUTLER, Judith. Relatar a si mesmo. Crítica da violência ética. Belo Horizonte: Autêntica, 2015.

SALLES, Atílio Catosso. Discurso e performance. Campinas: Pontes, 2018.

YURA, Alice. Guerrilha (foto performance). 2014. 1 fot., color. 65 x $100 \mathrm{~cm}$. Arquivo pessoal.

SUBMETIDO EM: 07/10/2021

ACEITE EM: 22/10/2021 